\title{
Resíduos de Glifosato e AMPA em fórmula infantil à base de soja: monitoramento do mercado brasileiro
}

\section{Giovanna Sevilha Ferreira*, Nadia Regina Rodrigues, Ana Paula Ferreira Souza}

\section{Resumo}

O glifosato é um herbicida amplamente utilizado no mundo, sendo aplicado em diversas culturas, dentre elas soja. O glifosato e seu metabólito, AMPA têm sido apontados como possíveis contribuintes para o surgimento de várias doenças, como o câncer. Formulas infantis à base de soja têm sido uma alternativa para evitar o leite de vaca por diferentes motivos, como a intolerância alimentar. A presença de resíduos de glifosato e AMPA foi avaliada em 10 fórmulas infantis à base de soja de diferentes lotes por método previamente validado.

\section{Palavras-chave:}

Toxicologia, Glifosato, Herbicida

\section{Introdução}

A soja geneticamente modificada, tolerante ao glifosato é cultivada em aproximadamente $93 \%$ das plantações no Brasil. Alergias alimentares afetam cerca de $8 \%$ da população infantil mundial nos primeiros 3 anos de vida. Muitas alternativas ao leite de vaca estão disponíveis, como leite de soja. O Brasil não possui legislação específica para o controle de resíduos de pesticidas em alimentos processados. Estudos tem apontado o glifosato e seu metabólito AMPA como possíveis contribuintes para o surgimento de várias doenças, como o câncer. Através do monitoramento de amostras comerciais é possível verificar se há contribuição significativa na exposição ao glifosato e AMPA pelos consumidores ${ }^{1}$.

\section{Resultados e Discussão}

Tabela 1. Recuperação de Glifosato e AMPA Nível

Identificação fortificação mg. kg-1

$\begin{array}{cc}\text { I baixa } & 0,02 \\ \text { I alta } & 1 \\ \text { II baixa } & 0,02 \\ \text { II alta } & 1 \\ \text { III baixa } & 0,02 \\ \text { III alta } & 1 \\ \text { IV baixa } & 0,02 \\ \text { IV alta } & 1\end{array}$

Recuperação (\%) Glifosato AMPA

77

88

90

91

90

78

82

92

93

79

82

84

90

80

86

80

As 10 amostras de fórmulas infantis a base de soja foram analisadas em triplicata a partir de lotes diferentes de 2 marcas comerciais. A determinação dos resíduos de glifosato e AMPA seguiram o procedimento de Cowell ${ }^{2}$, 1986 com a extração dos compostos em meio ácido, limpeza do extrato por resina quelante, cromatografia de troca iônica e analise com cromatografia líquida. A recuperação do glifosato e AMPA obtidas das amostras fortificadas estão demonstradas na tabela 1.

A média dos níveis de glifosato e AMPA encontrados nas amostras estão demonstrados na tabela 2. O limite de quantificação (LOQ) do glifosato e AMPA foi de 0,02 mg.kg-1.
Tabela 2. Resíduos de Glifosato e AMPA

$\begin{array}{ccc}\text { Identificação } & \begin{array}{c}\text { Média } \\ \text { Glifosato } \\ \left(\mathrm{mg}^{\mathrm{kg}}{ }^{-1}\right)\end{array} & \begin{array}{c}\text { Média } \\ \text { AMPA } \\ \left(\mathrm{mg} \cdot \mathrm{kg}^{-1}\right)\end{array} \\ \text { M1 } & 0,267 & 0,072 \\ \text { M2 } & 0,269 & 0,027 \\ \text { M3 } & 0,425 & 0,019 \\ \text { M4 } & 0,461 & 0,050 \\ \text { M5 } & 0,357 & 0,016 \\ \text { M6 } & 0,145 & 0,023 \\ \text { M7 } & 0,195 & 0,023 \\ \text { L1 } & 0,696 & 0,191 \\ \text { L2 } & 0,384 & 0,022 \\ \text { L3 } & 0,791 & 0,234\end{array}$

A marca $L$ apresentou a maior concentração média de glifosato e AMPA entre as duas marcas, sendo a concentração média de glifosato $0,624 \mathrm{mg} \cdot \mathrm{kg}^{-1}$ e de AMPA de $0,149 \mathrm{mg} \cdot \mathrm{kg}^{-1}$, enquanto as médias da marca $\mathrm{M}$ foram mg. $\mathrm{kg}^{-1}$ para o glifosato e mg. $\mathrm{kg}^{-1}$ para o AMPA.

\section{Conclusões}

O presente estudo aponta a presença de glifosato e AMPA acima do LOQ em $100 \%$ das amostras analisadas. $O$ controle de qualidade das formulações de leite de soja não é tão rígido devido a falta de legislação para alimentos processados no Brasil, portanto estudos devem ser realizados para o cálculo da ingestão diária e avaliação de risco.

\section{Agradecimentos}

O presente trabalho foi conduzido com auxílio da bolsa concedida pelo CNPQ.

\footnotetext{
${ }^{1}$ Rodrigues NR \& Souza APF (2018) Occurrence of glyphosate and AMPA residues in soy-based infant formula sold in Brazil, Food Additives \& Contaminants: Part A, 35:4, 723-730.

${ }^{2}$ Cowell JE, Kunstman JL, Nord PJ, Steinmetz JR, Wilson GR. 1986. Validation of an analytical residue method for analysis of glyphosate and metabolite: an interlaboratory study. J Agricul Food Chem. 34:955-960
} 